\title{
SINGLE SETTING ERCP AND LAPAROSCOPIC CHOLECYSTECTOMY IS A SAFE PROCEDURE IN PATIENTS WITH CHOLECYSTO-CHOLEDOCHOLITHIASIS: A PROSPECTIVE STUDY IN A PERIPHERAL-LEVEL HOSPITAL
}

\author{
Pokhrel N, ${ }^{1,2}$ Katwal G
}

${ }^{1}$ Department of Surgery, ${ }^{1}$ Lumbini Medical College and Teaching Hospital, Department of Surgery, Palpa 32500,

Lumbini, ${ }^{2}$ Nepal Medical College Teaching Hospital, Attarkhel, Gokarneshwor-8, Kathmandu, Nepal, Chitwan Medical College Teaching Hospital, ${ }^{3}$ Department of Surgery, Bharatpur, Chitwan 44200, Nepal

\begin{abstract}
The ideal management of cholecysto-choledocholithiasis is an open cholecystectomy (OC) with the common bile duct (CBD) exploration worldwide. The single setting 2-stage approach- endoscopic retrograde cholangiopancreatography (ERCP), endoscopic sphincterotomy (EST), and CBD clearance followed by laparoscopic cholecystectomy (LC) offers an advantage, mainly by reducing the hospital stay, the cost, and the morbidity. The Objective of the study is to compare the ERCP+LC single setting approach with an $\mathrm{OC}+\mathrm{CBD}$ exploration for the treatment of cholecysto-choledocholithiasis. This is an interim analysis of 160 patients with 83 (51.9\%) patients in ERCP+LC and 77 (48.1\%) in an open procedure (OC+CBD exploration) group respectively. We did a prospective study in patients admitted for the management of the cholecysto-choledocholithiasis in the Department of Surgery at the Lumbini Medical College and Teaching Hospital from November 2012-October 2015. They underwent 2-stage ERCP+LC in a single setting and we compared them with 2-stage OC+CBD exploration in a single setting approach. The patients with the open procedure were our control group. All the included cases in the study were elective. The procedure was feasible in our hospital. Similarly, the hospital stay was significantly shorter in the ERCP+LC group; $3.92 \pm 0.719$ days vs $10.30 \pm 1.557$ days, $\mathrm{p}<0.05$. There was a significant difference in the total morbidity of ERCP+LC group 7 (8.4\%) vs 14 (18.2\%), $p$ $<0.05$. Here, wound infection in the ERCP+LC group was $2(2.4 \%)$ vs $4(5.2 \%)$ and there was one case of abdominal collection 1 (1.2\%) which was managed symptomatically. The incidence of retained CBD stone in the ERCP+LC was $3(1.2 \%)$ which was managed successfully with ERCP. In all the cases, postERCP amylase value was found to be within the normal limit. The result of our study suggests, single setting ERCP+LC at the peripheral-level hospital is feasible in terms of cost, length of hospital stay, morbidity and stone clearance.
\end{abstract}

\section{KEYWORDS}

Common bile duct stones, Endoscopic Retrograde Cholangiopancreatography, Laparoscopic Cholecystectomy Open Cholecystectomy

\section{CORRESPONDING AUTHOR}

Dr. Nabin Pokhrel

Associate Professor,

Department of Surgery,

Nepal Medical College Teaching Hospital

Gokarneshwor-8, Kathmandu, Nepal

Email: nabin.pokharel@gmail.com

Orcid ID: 0000-0002-8981-3336

DOI: https://doi.org/10.3126/nmcj.v22i1-2.30038 


\section{INTRODUCTION}

Choledocholithiasis is the cause of significant morbidity and mortality due to its complications in the form of gallstone pancreatitis, obstructive jaundice, and cholangitis. The incidence ranges from 5 to $15 \%$ and up to $20 \%$ in the elderly population. ${ }^{1}$ And, up to $25 \%$ of cases, CBD stones are discovered intraoperatively. ${ }^{2}$ The primary imaging modalities like Transabdominal USG has the sensitivity of $73 \%$ and specificity of $91 \%{ }^{3}$ Similarly, MRCP has the sensitivity of $81-100 \%$ and specificity of $92-100 \%$ whereas, ERCP/EUS has 88-97\% and $96-100 \% .^{4-6}$ These imaging modalities can detect CBD stones as well as dilated biliary ductal system. Other modalities available are Liver function test (LFT), ${ }^{3}$ intraoperative laparoscopic ultrasonography and helical CT cholangiography. ${ }^{4-6}$

Laparoscopic cholecystectomy with or without intraoperative cholangiogram (IOC) is the current gold standard for the treatment of acute or chronic cholecystitis. $^{7-9}$ There is no single method or algorithm that is superior to others when it comes in the treatment of the obstructive complication of calculous biliary diseases like jaundice, pancreatitis, cholangitis, and asymptomatic choledocholithiasis. ${ }^{8,10}$ There has been a drastic transformation in the management of CBD stones after the introduction of ERCP in $1968 .{ }^{11}$ Recently, Aleknaite et al. ${ }^{12}$ showed that ERCP has a better diagnostic performance than IOC. Traditionally, the treatment involves what is known as a twosetting procedure, that consists of preoperative ERCP followed by LC. Alternatively, LC with IOC and intraoperative CBD exploration or ERCP performed at a later date in the traditional twostep framework..$^{13}$ A recent systemic review and meta-analysis recommended ERCP followed by LC rather than ERCP followed by the wait and watch. Even though two groups had no differences in mortality, results showed that LC after ERCP could be done safely including high risk patients. ${ }^{14,15}$
In the United States nationwide assessment for the treatment of CBD stone showed drastic increase in the use of ERCP+LC from $52.8 \%$ to $85.7 \%(p<0.001)$ and decrease in the trend of open CBDE (30.6\% vs $5.5 \% ; p<0.001)$ and laparoscopic CBDE (9.2\%vs $3.0 \% ; p<0.001){ }^{16}$ Safety and efficacy of single setting ERCP+LC were shown in the RCT done by Cuschieri et al. ${ }^{17}$ long back. Where they found that with the proper selection of the patients, ERCP+LC leads to the better management of patients with CBD stones. Here, in our study both the procedures $(\mathrm{ERCP}+\mathrm{LC})$ had been done in a single setting by a single team at the peripheral-level hospital. And thus the primary objective of this study is to check the feasibility of the procedure, whereas secondary objectives are to (1) detect the morbidity (cholangitis, pancreatitis, abdominal collection and wound infection), (2) the length of hospital stay, and (3) stone clearance, respectively. The new thing about this study is that all of these procedures ERCP and LC were performed at the single setting by the same surgeon who was trained for the ERCP, LC and open procedure, respectively.

\section{MATERIALS AND METHODS}

This was a prospective study done on patients admitted for management of the cholecystocholedocholithiasis in the Department of Surgery at the Lumbini Medical College and Teaching Hospital from November 2012-October 2015. The patients were followed up for 1 year after the surgery. This is a peripheral setting hospital located in a remote city of Nepal-"Palpa". The study was approved by the institutional ethical committee-"IRB of Lumbini Medical College and Teaching Hospital" and written consent was obtained from all of the patients. This study had been registered at ClinicalTrials.govNCT04213092. A comprehensive literature search published in English was done till 2019 using Hinari, PubMed, Cochrane Library, EMBASE, Web of Science, and ScienceDirect.

Table1: The Inclusion and exclusion criteria's for ERCP + Laparoscopic cholecystectomy. CBDCommon Bile Duct; ERCP - Endoscopic Retrograde Cholangiopancreatography

SN. Inclusion criteria SN. Exclusion criteria

1. All the sonological proven cases of choledocholithiasis with cholelithiasis

2. $\quad$ BD diameter $<2 \mathrm{~cm}$.

2. liver mass or abscess, neoplasm, Suppurative or necrotizing cholecystitis, gall bladder empyema, or perforation, Pregnancy. 
Table 2: The inclusion and exclusion criteria's for open cholecystectomy and CBD explorations. CBD-Common Bile Duct; ERCP- Endoscopic Retrograde Cholangiopancreatography.

\section{Criteria for Open cholecystectomy and CBD exploration}

SN. Inclusion criteria.

1. 1 . CBD stone $>2 \mathrm{~cm}$.

2. 2. Distally impacted stone $>1.5 \mathrm{~cm}$.

3. 3. Multiple stones each $>1.5 \mathrm{~cm}$.
SN.

1.

2. Evidence of cirrhosis, intrahepatic gallbladder, liver mass or abscess, neoplasm.

3. Suppurative or necrotizing cholecystitis, gallbladder empyema, or perforation Pregnancy.
This is an interim analysis of 160 patients with 83 (51.9\%) patients in ERCP+LC and 77 (48.1\%) in open procedure (OC with CBD exploration) group respectively. The primary objective was to compare the single setting ERCP+LC with OC+CBD exploration and the secondary objectives were to study (1) the feasibility of the procedure, (2) detect the morbidity (cholangitis, pancreatitis, abdominal collection, and wound infection), (3) the length of stay, and (4) the stone clearance, respectively. We defined our single-setting procedure as ERCP followed by LC. The patients from an open procedure group were those who underwent the procedure before our team was trained to carry out the ERCP. This open procedure group also included 10 patients who underwent open surgery due to unsuccessful ERCP. And finally, we compared ERCP+LC group with those who underwent the open procedure. The inclusion and exclusion criteria's for ERCP+LC and open procedure are shown in Table 1 and Table 2, respectively.

After being informed about the related therapeutic maneuver, the patients were chosen for the sequence of endoscopic procedure and LC. And, the unsuccessful patients underwent through the OC with CBD exploration along with choledochoscopy. General anesthesia with nasal endotracheal intubation was done in all the patients. Antibiotic prophylaxis was given according to the standard recommendation for cholecystectomy. ${ }^{18}$ The ERCP procedure was performed with the patients in the prone position. A duodenoscope (TJF160R, Fujinon, Japan) was inserted into the second segment of duodenum via the mouth. A cholangiogram was carried out using C-arm X-ray (SIEMENS) and an EST was performed to extract the CBD stones. The stones were removed by basket or balloon catheter. Stones larger than $10 \mathrm{~mm}$ were removed using a mechanical lithotripter. Following ERCP, care was taken to remove all the gas from the stomach to facilitate LC. The patients were then placed in the reverse Trendelenburg position. LC was performed using the four trocar technique.
A sub-hepatic drain was positioned if there was any concern about the possible bile leakage or bleeding in the postoperative period.

In cases of failed ERCP, the patients were placed in the supine position and OC with CBD explorations were performed at the same setting. A right subcostal incision was given for the open surgery. Cholecystectomy was performed ante-grade or retro-grade technique depending upon the anatomical variations of the gallbladder. CBD was opened below the opening of the cystic duct and stone clearances were done. To assure the stone clearances intraoperative choledochoscopies were performed. All the procedure viz. ERCP, LC, and open surgeries were performed by an experienced single surgeon and his team.

The statistical data were analyzed with a $t$-test, Pearson's $\chi^{2}$, Fisher's exact test, Mann Whitney's test, and Kruskal Wallis test using a statistical analysis program (SPSS 16), $p<0.05$ was considered statistically significant.

\section{RESULTS}

Patient Characteristics: In total 160 patients were included for the study. Where 83 (51.9\%) patients in $(\mathrm{ERCP}+\mathrm{LC})$ group met the criteria out of 93 (58.1\%) patients. And, $10(6.2 \%)$ out of 93 were converted to open procedure and were included in the total number of the open procedure (the control group). The total number of open procedures were $77(48.1 \%)$. Out of ten, $2(2.1 \%)$ had difficult cannulation due to the edematous duodenal wall, $3(3.2 \%)$ had bleeding from the ampullary site and in 5 (5.4\%) patients stone was large and we were unable to break it due to its hardness.

The age range was between 13 years to 76 years, with the mean age of $44.2 \pm 17.1$ in the ERCP+LC group and $65 \pm 12.1$ in the open CBD exploration group. The difference between the age of the patients between these two groups was found to be statistically significant. Here, those who 
underwent the open procedure were older than the group of patients who underwent through successful ERCP+LC. This non-homogeneity in the age could be a subject to bias. And, when we consider the sex of the patient across the group, the total number of a male patient in the ERCP+LC group were $16(19.3 \%)$ and female patients were $67(80.7 \%)$, respectively. Whereas, the total number of male patients in the open group were $14(18.2 \%)$ and female patients were $63(81.8 \%)$ respectively. The difference between the male and female across the groups were statistically significant, $p<0.005$ this means the females were found to have more incidences of gallstones in this study. Similarly, demographical and clinical characteristic showed the significant difference between the male and female patients $(p<0.05)$, since the diagnosis understudy was commonly seen in female patients.

Comparison between $E R C P+L C$ and the open group: When analyzing the data, the size of the $\mathrm{CBD}$ in ERCP+LC group was $9.7 \pm 1.7 \mathrm{~mm}$ and in
OC+CBD exploration group was $23.5 \pm 2.2 \mathrm{~mm}$ respectively. The difference was statistically significant $(p<0.05)$. Whereas, total leucocyte counts (TLC), level of preoperative bilirubin, liver transaminase levels and alkaline phosphatase were statistically not significant $(p>0.05)$ as compared to the conversion to open procedure as shown in and Table 4 and Fig. 1 and 2. Also, the infectious complication in ERCP+LC group was found to be less than OC+CBDE group (18.2\% vs 8.5\%), $p<0.05$ Fig. 1 and 2 and Table 3.

The mean duration of surgery for ERCP+LC and $\mathrm{OC}+\mathrm{CBD}$ exploration were $82.2 \pm 11.1$ and $124.7 \pm 10.2$ minutes respectively and were statistically significant $(p<0.05)$. The serum amylase in the postoperative period was not significantly associated with the type of procedure $(p<0.05)$. Whereas, postoperative complications were significant in the case of open procedure in the form of minor wound infection and fever $(p<0.05)$. Similarly, the mean number of the postoperative days of stay was $3.9 \pm 0.7$ in $\mathrm{ERCP}+\mathrm{LC}$

Table 3: Shows comparison of complications between OC+CBDE and ERCP+LC. The infectious complication in ERCP+LC group was found to be less than OC+CBDE group (18.2\% vs 8.5\%), $p$

$<0.05$, CBD- Common Bile Duct, ERCP- Endoscopic Retrograde Cholangiopancreatography, OCOpen cholecystectomy; TLC- Total Leukocyte Counts

\begin{tabular}{lll} 
Complications & ERCP+LC & OC+CBD Exploration \\
\hline Fever & $4(4.8 \%)$ & $10(13 \%)$ \\
Wound infection & $2(2.4 \%)$ & $4(5.2 \%)$ \\
Abdominal collection +fever + TLC & $1(1.2 \%)$ & - \\
Total & $7(8.4 \%)$ & $14(18.2 \%)$ \\
$p$-value & $<0.05$ & \\
\hline
\end{tabular}

Table 4: Comparison of variables of OC+CBDE and ERCP+LCBDE procedure, $P<0.05$ significant, LFT- Liver function test, CBD- Common bile duct

\begin{tabular}{lccc} 
Parameters & ERCP+LC & OC+CBD & P-value \\
\hline Age & $44.2 \pm 517.1$ & $65 \pm 12.1$ & $>0.05$ \\
Sex & & & \\
Male & $16(19.3 \%)$ & $14(18.2 \%)$ & 0.000 \\
Female & $67(80.7 \%)$ & $63(81.8 \%)$ & \\
CBD size & $9.67 \pm 1.7 \mathrm{~mm}$ & $23.5 \pm 2.2 \mathrm{~mm}$ & $<0.05$ \\
LFT (Liver function test) & Non-significant & Non-significant & $>0.05$ \\
Serum amylase rise in post-operative period & Non-significant & Non-significant & $>0.05$ \\
Duration of Ssurgery & $82.2 \pm 11.1$ mins & $124.7 \pm 10.2$ mins & $<0.05$ \\
Length of stay & $3.9 \pm 0.7$ days & $10.3 \pm 1.5$ days & $<0.05$ \\
Follow up incidence of retained stone in 3 months & $3(1.2 \%)$ & none & $>0.05$ \\
\hline
\end{tabular}


Table 5: Summary of Randomized controlled trial comparing two stage (ERCP+ LC) vs.

one stage (LC+LCBDE) ${ }^{46}$ and its comparison with our results; n- Number of Patients; LC-

laparoscopic cholecystectomy; ERCP- endoscopic retrograde cholangiopancreatography; F/B-

followed by; LCBDE- laparoscopic common bile duct exploration; PO- post-operative stay; "Two stage- endoscopy followed by surgery; ${ }^{*}$ One stage LCBDE or intra-operative endoscopy.

\begin{tabular}{|c|c|c|c|c|c|c|c|c|c|c|}
\hline 胥 & 䓪 & 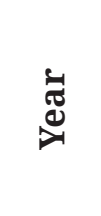 & 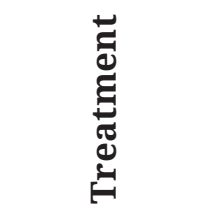 & = & 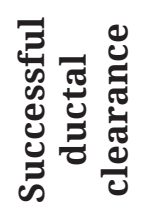 & : & 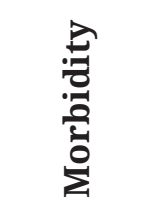 & 窟 & 苞 & 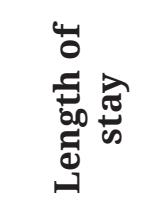 \\
\hline \multirow{2}{*}{1.} & \multirow{2}{*}{ Rhodes } & \multirow{2}{*}{1998} & $\mathrm{LC}+\mathrm{ERCP}$ & 40 & 37 & 0 & 6 & 4 & 10 & 3.5 \\
\hline & & & $\mathrm{LC}+\mathrm{LCBDE}$ & 40 & 30 & 0 & 7 & 2 & 10 & 1 \\
\hline \multirow{2}{*}{2.} & \multirow{2}{*}{ Cuschieri } & \multirow{2}{*}{1999} & $\mathrm{ERCP}+\mathrm{LC}$ & 133 & 82 & 2 & 17 & 9 & 17 & 9 \\
\hline & & & $\mathrm{LC}+\mathrm{LCBDE}$ & 133 & 92 & 1 & 21 & 9 & 17 & 6 \\
\hline \multirow{2}{*}{3.} & \multirow{2}{*}{ Sgourakis } & \multirow{2}{*}{2002} & $\mathrm{ERCP}+\mathrm{LC}$ & 42 & 27 & 1 & 6 & 3 & 5 & 9 \\
\hline & & & LC+LCBDE & 36 & 24 & 1 & 5 & 2 & 4 & 7.4 \\
\hline \multirow{2}{*}{4.} & \multirow{2}{*}{ Nathanson } & \multirow{2}{*}{2005} & LC+ERCP & 45 & 43 & 0 & 11 & 6 & 3 & 7.7 \\
\hline & & & $\mathrm{LC}+\mathrm{LCBDE}$ & 41 & 40 & 0 & 12 & 7 & 3 & 6.4 \\
\hline \multirow[b]{2}{*}{5.} & \multirow[b]{2}{*}{ Morino } & \multirow[b]{2}{*}{2006} & ERCP+LC & 45 & 36 & 0 & 4 & 2 & 15 & 8 \\
\hline & & & $\begin{array}{c}\text { LC+IOP } \\
\text { ERCP }\end{array}$ & 46 & 44 & 0 & 5 & 4 & 2 & 4.3 \\
\hline \multirow{2}{*}{6.} & \multirow[t]{2}{*}{ Noble } & \multirow{2}{*}{2009} & $\mathrm{ERCP}+\mathrm{LC}$ & 47 & 29 & 1 & 16 & 8 & 18 & $\begin{array}{l}3 \text { (PO } \\
\text { stay) }\end{array}$ \\
\hline & & & $\mathrm{LC}+\mathrm{LCBDE}$ & 44 & 38 & 0 & 23 & 8 & 0 & $\begin{array}{l}5 \text { (PO } \\
\text { stay) }\end{array}$ \\
\hline \multirow{2}{*}{7.} & \multirow{2}{*}{ Rogers } & \multirow{2}{*}{2010} & $\mathrm{ERCP}+\mathrm{LC}$ & 55 & 30 & 0 & 5 & 0 & 1 & 5 \\
\hline & & & $\mathrm{LC}+\mathrm{LCBDE}$ & 57 & 15 & 0 & 6 & 0 & 2 & 4 \\
\hline \multirow{2}{*}{8.} & \multirow{2}{*}{ Bansal } & \multirow{2}{*}{2010} & $\mathrm{ERCP}+\mathrm{LC}$ & 15 & 13 & 0 & 5 & 2 & 2 & 4 \\
\hline & & & $\mathrm{LC}+\mathrm{LCBDE}$ & 15 & 14 & 0 & 6 & 2 & 1 & 4.2 \\
\hline \multirow[b]{2}{*}{9.} & \multirow[b]{2}{*}{ Tzovaras } & \multirow[b]{2}{*}{2011} & $\mathrm{ERCP}+\mathrm{LC}$ & 49 & 45 & 0 & 6 & 5 & 5 & 5.5 \\
\hline & & & $\begin{array}{c}\text { LC+IOP } \\
\text { ERCP }\end{array}$ & 50 & 47 & 1 & 7 & 6 & 3 & 4 \\
\hline \multirow{2}{*}{10.} & \multirow{2}{*}{ Our Study } & \multirow{2}{*}{2018} & $\mathrm{OC}+\mathrm{ECBDE}$ & 77 & $100 \%$ & 0 & $18.2 \%$ & & $0 \%$ & $10.3 \pm 1.5$ \\
\hline & & & $\mathrm{LC}+\mathrm{ERCP}$ & 83 & $96.3 \%$ & 0 & $8.4 \%$ & & $3.7 \%$ & $3.9 \pm 0.7$ \\
\hline & \multirow{2}{*}{ TOTAL } & & Two stage* & 471 & $\begin{array}{c}342 \\
(72.6 \%)\end{array}$ & $\begin{array}{c}4 \\
(0.8 \%)\end{array}$ & $\begin{array}{c}76 \\
(16.1 \%)\end{array}$ & $\begin{array}{c}39 \\
(8.3 \%)\end{array}$ & $\begin{array}{c}76 \\
(16.6 \%)\end{array}$ & \\
\hline & & & One stage ${ }^{\#}$ & 462 & $\begin{array}{c}344 \\
(74.4 \%)\end{array}$ & $\begin{array}{c}3 \\
(0.6 \%)\end{array}$ & $\begin{array}{c}92 \\
(19.9 \%)\end{array}$ & $\begin{array}{c}40 \\
(8.6 \%)\end{array}$ & $42(9 \%)$ & \\
\hline
\end{tabular}

group and $10.3 \pm 1.5$ days in $\mathrm{OC}+\mathrm{CBD}$ exploration group respectively. And, it was statistically significant $(p<0.05)$ as shown in Table 3 and 4 and Fig. 1 and 2 .

The stone clearance rate was $100 \%$ in the open group at 3 months follow up as compared to the ERCP+LC group which was $96.3 \%$. The USG findings were abnormal in the form of prominent CBD but without stones in the OC+CBD exploration group. Whereas, there were 3 cases of $(3.6 \%)$ of retained stones in ERCP+LAP cholecystectomy group and were successfully managed with ERCP. The patients were also followed up with LFT who had prominent CBD and were found to be within normal limits. And, the incidence of retained stones between these groups was not statistically significant $(p>0.05)$.

\section{DISCUSSION}

The most common cause for obstructive jaundice and recurrent cholangitis are due to the $\mathrm{CBD}$ stones. And, most of the CBD stones are secondary 
as only $15 \%$ of the cases are primary CBD stones. ${ }^{1,4}$ These can cause significant morbidity and mortality, thus these patients need to be adequately evaluated before the surgery. ${ }^{13,19}$ To provide comprehensive treatment to these patients, biliary surgeons must master more than one techniques in the current era. The endoscopic procedures have made a significant impact on the treatment of gallstone diseases in the last 3 decades. But their diagnostic usefulness has been taken over by other non-invasive modalities in the management of benign biliary diseases. ${ }^{20}$

Novel techniques like LC-LCBDE (laparoscopic cholecystectomy-laparoscopic bile duct exploration), LC-EST ${ }^{21}$ and laparoscopicendoscopic rendezvous (LREV) have shown exciting results. However, a recent meta-analysis from Cochrane Library failed to determine the effect of LREV vs ERCP on morbidity and mortality. $^{22}$ Similarly, other modalities like laparoscopic Transcystic (TC) and Transductal (TD) has emerged for the extraction of CBD stones. These study showed that TC and ERCP/EST has similar results compared to the TD approach. ${ }^{23}$ A systemic review failed to show a significant difference in the morbidity, mortality, retained stones, and failure rate between LCBDE and ERCP. ${ }^{8}$ Yet, a recent meta-analysis showed that $\mathrm{LCBDE}+\mathrm{LC}$ is superior to $\mathrm{ERCP}+\mathrm{LC}$ for $\mathrm{GB}$ stone and CBD stone in terms of perioperative safety as well as short and long-term postoperative efficacy. ${ }^{24}$ These revolutionary techniques need specialized facilities with trained personnel. The argument against and for the laparoscopic CBD exploration is related to the patient's factor viz. the diameter of $\mathrm{CBD}<8 \mathrm{~mm}$, multiple stones/distal impaction, cost, and duration of the anesthesia and the feasibility related factor in the remote center respectively. Moreover, when two procedures are performed by the two separate teams at the same time, it may lead to technical difficulties. But, in our study this difficulty was overcome as both the procedures were performed by the same team with experience in these procedures at the peripheral-level hospital. And, we compared $\mathrm{ERCP}+\mathrm{LC}$ with $\mathrm{OC}+\mathrm{CBD}$ exploration in a singlesetting by a single team.

In our study, the success rate of stone clearance was $89.2 \%$ (83 out of 93) which is comparable to a study done by Koc et al. ${ }^{25}$ where they reported the success rate of stone clearance of $94.4 \%$. In their series, $5.5 \%$ of patients required multiple ERCP interventions, for retained stones but in our series, we immediately operated the patient with the intraoperative choledochoscopy and CBD exploration at the same setting with the success rate of $100 \%$. We justify our approach of conversion in case of difficulties and the patients were preoperatively counseled regarding the procedure. As our experience was of the peripheral-level hospital, it was very difficult to convince the patients to undergo through the second ERCP procedure. Also, failure of the ERCP was not due to the technical error rather it was due to the high burden of stones, the size $(>2.5 \mathrm{~cm})$ and impaction of the stone at the distal end of the CBD. Thus, in our scenario laparoscopic CBD exploration was not an option and our open approach in those 10 cases were understandable. Our result is better than a study done by Cinar et $a l^{26}$ where conversion to open cholecystectomy was $11.3 \%$ following single ERCP and $29.2 \%$ following two or more ERCP respectively. $\mathrm{ERCP}+\mathrm{LC}$ related complications were $7(8.4 \%)$ in our study and it includes only minor complications. But, one of the cases had intraabdominal collection post-surgery and it was managed symptomatically. If we observe the types of complications we encountered, no patients in our study had evidence of pancreatitis and cholangitis following the procedure. However, the milder complications that we encountered, were tackled in the OPD basis. This gives our study a new thought that it can be done at the peripheral setting very safely, where we do not have the luxury of an experienced gastroenterologist who is going to help during the procedure and/or in the follow-up procedure.

Our result is comparable to other series where ERCP-associated complication rate was $11.1 \%{ }^{25}$ Whereas, complication rates in our open group was $14(18.2 \%)$ which were minor complications like fever and wound infections. And, they were successfully managed with symptomatic treatment. Tzovaras et $a l^{27}$ noted a significant decrease in the length of hospital stay and postoperative serum amylase values by using a novel single-setting procedure LERV technique. Rábago et $a l^{28}$ also compared a single setting to a double setting approach. The group receiving the single-setting approach with intraoperative ERCP exhibited a decrease in morbidity in addition to the shorter hospital stay and decreased hospital costs. The decrement in morbidity these group resulted from the lower rate of papillotomy and lower rates of post-ERCP pancreatitis. By limiting the number of operative procedures, patients can be safely and more efficiently treated using this method. The single setting technique of ERCP and LC is simply such a novel procedure at our institution that, it would be challenging to achieve this increased statistical power at other institutions of Nepal. These data for an example identifies a $3.7 \%$ rate of retained stone after ERCP. Anecdotally, the overall retained stone rate is around the vicinity of 5\%. The retained stone rate in some series has been documented to be as high as $12 \%{ }^{29}$ and as low as $2-4 \%$ as in our series. ${ }^{30,31}$ 
The success of ERCP in our series is comparable to the study of Zang et $a .^{32}$ The parameters like the stone clearance rate from the CBD, the duration of surgery, and the length of hospital stay were similar in both of the studies.

With regards to same setting surgery for patients with concomitant gallstones and choledocholithiasis, LCBDE is another good option that avoids duodenoscopy and LC. ${ }^{33}$ And the debate has been ongoing since long about the better method of management. Multiple RCTs showed that both of the methods viz. LCBDE+LC and ERCP+LC are equally effective in the diagnosis and the treatment of CBD stones. ${ }^{34,35}$ An Up-todate meta-analysis also showed that LCBDE+LC is superior to pre-EST+LC. ${ }^{24}$ According to European Society of Gastrointestinal Endoscopy (ESGE) guideline, ERCP (with EPBD rather than EST) should be done in CBD stones $<8 \mathrm{~mm}$ in size. ${ }^{36}$ Whereas, the ERCP may not be appropriate for the stone size of $>25 \mathrm{~mm}$ without a laser lithotriptor. And LCBDE or open CDBE with IOC would be a better option for larger stones and residual stones. ${ }^{37}$ However, LCBDE is limited to centers with appropriate expertise. ${ }^{2,36}$ A recent meta-analysis reported that intra-operative ERCP is superior to pre-operative ERCP in terms of exposure to anesthetic agents, higher incidence of pancreatitis, longer hospital stay and cost. ${ }^{38,39}$ Retrospective study of single setting approach done by Jones et al. ${ }^{40} \mathrm{LC}+\mathrm{IOC}$ then ERCP also showed a significant reduction in the cost and time for the treatment of CBD stones. They also found that ERCP was better than MRCP or LCBDE in terms of cost and time.

Fujimoto et $a l^{41}$ found pneumobilia as a significant risk factor for cholecystitis and recurrent CBD stones following the endoscopic procedure. They also noted that $53.8 \%$ of the patients developed GB cancer following the procedure but long-term evidence is lacking regarding the delayed effects of papillotomy. Also, Elgeidie et $a l^{42}$ showed that both LCwith intraoperative endoscopic sphincterotomy (IOES) and LC with laparoscopic CBD exploration (LCBDE) were minimally invasive and effective treatments that can be done safely for the management of cholecysto-choledocholithiasis. And they preferred LC-IOES provided the hospital has facilities with the experienced personnel. And a recent meta-analysis by Tang et $a l^{43}$ also supports this method. If we do LCBDE for larger stone with the laser lithotripsy then again the issues related to $\mathrm{T}$ - tube drainage will add on to the prolonged morbidity to the patient. Besides, if the stone clearance was not successful then open procedure has to be carried out for clearance of the stones. Finally, this justifies our approach at the peripheral-level hospital for the management of patients with cholecysto-choledocholithiasis. Table 5 summarizes and compares our study with a meta-analysis of one- vs. two-stage laparoscopic/ endoscopic management of CBD stones. ${ }^{44}$

The main strength of our study: It is a single setting procedure done by a single team and thus it is a revolutionary concept which is pragmatic with a $100 \%$ success rate as in our case. Therefore the results are applicable generally, not just to centers with specialized expertise but also at the peripheral centers. The burden of central referral, as well as the waiting period for both the procedures, was decreased in our study. This also led to the reduction in the duration of anesthesia, the length of hospital stay, the complications following the procedure and the financial burden respectively. Similarly, in case of rare complications of ERCP like bowel perforation and intra procedure bleeding, they can be tackled at the same setting by the open procedure.

The limitation of our study: It is a single center study with limited number of patients $(n=160)$ and two groups of patients were found to be inhomogeneous concerning to age and this makes it difficult to establish a clear consensus regarding larger stones in open group. Similarly, in cases of failed ERCP, multiple attempts of ERCP at the different interval were not consented due to geographic and economic condition.

In conclusion, endoscopic stone extraction and LC performed in the same setting is feasible and is safe in patients with gallstones and concomitant CBD stones. We propose that surgeons at the peripheral-level hospital experienced in both the procedures may attempt this procedure. This will reduce the total cost, time, referral and the morbidity of undergoing procedures in a higher setting as it is very safe and feasible according to our results.

\section{ACKNOWLEDGEMENTS}

Authors sincerely appreciate Prof. Yanfeng Wang, Institute of Hepatobiliary Diseases of Wuhan University, Transplant Center of Wuhan University, Hubei Key Laboratory of Medical Technology on Transplantation and Deputy Director and Associate Professor Hong Yan from Department of Epidemiology and Health Statistics, School of Public Health, Wuhan University, Wuhan, China for her valuable support and suggestions on the data analysis. Especial thanks to all the Faculty members of Department of Surgery and Anesthesia, mainly Dr. Pradeep Timilsena from Department of Anesthesia, Lumbini Medical College and Teaching Hospital, who participated in this study with great enthusiasm and cooperation. 
Also, we thank Mrs. Bimala Guragain for her advices during manuscript designing and recent paper search on this topic.

The authors' responsibilities were as follows:NP and GK are the first authors. NP designed, and conducted the research. NP and GK were responsible for the data collection, analysis, interpretation, and drafting. And final approval of the manuscript was given by both the authors. The authors have no conflicts of interest to declare.

\section{REFERENCES}

1. European Association for the Study of the Liver (EASL). Electronic address: easloffice@easloffice. eu. EASL Clinical Practice Guidelines on the prevention, diagnosis and treatment of gallstones. J Hepatol 2016; 65: 146-81.

2. ASGE Standards of Practice Committee, Maple JT, Ikenberry SO, Anderson MA, Appalaneni V, Decker GA et al. The role of endoscopy in the management of choledocholithiasis. Gastrointest Endosc 2011; 74: 731-44.

3. Gurusamy KS, Giljaca V, Takwoingi Y et al. Ultrasound versus liver function tests for diagnosis of common bile duct stones. Cochrane Database Syst Rev 2015; : CD011548.

4. Miletic D, Uravic M, Mazur-Brbac M, Stimac D, Petranovic D, Sestan B. Role of magnetic resonance cholangiography in the diagnosis of bile duct lithiasis. World J Surg 2006; 30: 1705-12.

5. Freitas M-L, Bell R-L, Duffy A-J. Choledocholithiasis: evolving standards for diagnosis and management. World J Gastroenterol 2006; 12: 3162-7.

6. Virzì V, Ognibene NMG, Sciortino AS, Culmone G, Virzì G. Routine MRCP in the management of patients with gallbladder stones awaiting cholecystectomy: a single-centre experience. Insights Imaging 2018; 9: 653-9.

7. Song G-M, Bian W, Zeng X-T, Zhou J-G, Luo Y-Q, Tian X. Laparoscopic cholecystectomy for acute cholecystitis: early or delayed?: Evidence from a systematic review of discordant meta-analyses. Medicine (Baltimore) 2016; 95: e3835.

8. Dasari BVM, Tan CJ, Gurusamy KS et al. Surgical versus endoscopic treatment of bile duct stones. Cochrane Database Syst Rev 2013; : CD003327.

9. Gómez-Torres GA, González-Hernández J, LópezLizárraga CR et al. Intraoperative cholangiography versus magnetic resonance cholangiography in patients with mild acute biliary pancreatitis: A prospective study in a second-level hospital. Medicine (Baltimore) 2018; 97: e12976.

10. Gurusamy KS, Giljaca V, Takwoingi $\mathrm{Y}$ et al. Endoscopic retrograde cholangiopancreatography versus intraoperative cholangiography for diagnosis of common bile duct stones. Cochrane database Syst Rev 2015; : CD010339.

11. Singla S, Piraka C. Endoscopic retrograde cholangiopancreatography. Clin liver Dis 2014; 4: 133-7.

12. Aleknaite A, Simutis G, Stanaitis J, Valantinas J, Strupas K. Risk assessment of choledocholithiasis prior to laparoscopic cholecystectomy and its management options. United Eur Gastroenterol J 2018; 6: 428-38.

13. Lee A, Min SK, Park JJ, Lee HK. Laparoscopic common bile duct exploration for elderly patients: as a first treatment strategy for common bile duct stones. J Korean Surg Soc 2011; 81: 128-33.

14. Zhu H-Y, Xu M, Shen H-J et al. A meta-analysis of single-stage versus two-stage management for concomitant gallstones and common bile duct stones. Clin Res Hepatol Gastroenterol 2015; 39: 584-93.

15. Khan MA, Khan Z, Tombazzi CR, Gadiparthi C, Lee W, Wilcox CM. Role of Cholecystectomy After Endoscopic Sphincterotomy in the Management of Choledocholithiasis in High-risk Patients: A Systematic Review and Meta-Analysis. J Clin Gastroenterol 2018; 52: 579-89.

16. Wandling MW, Hungness ES, Pavey ES et al. Nationwide Assessment of Trends in Choledocholithiasis Management in the United States From 1998 to 2013. JAMA Surg 2016; 151: 1125-30.

17. Cuschieri A, Lezoche E, Morino $\mathrm{M}$ et al. E.A.E.S. multicenter prospective randomized trial comparing two-stage vs single-stage management of patients with gallstone disease and ductal calculi. Surg Endosc 1999; 13: 952-7.

18. Gomi H, Solomkin JS, Takada $\mathrm{T}$ et al. TG13 antimicrobial therapy for acute cholangitis and cholecystitis. J Hepatobiliary Pancreat Sci 2013; 20: 60-70.

19. Riciardi R, Islam S, Canete JJ, Arcand PL, Stoker ME. Effectiveness and long-term results of laparoscopic common bile duct exploration. Surg Endosc 2003; 17: 19-22.

20. Yokoe M, Hata J, Takada T et al. Tokyo Guidelines 2018: diagnostic criteria and severity grading of acute cholecystitis (with videos). J Hepatobiliary Pancreat Sci 2018; 25: 41-54.

21. Gao Y-C, Chen J, Qin Q et al. Efficacy and safety of laparoscopic bile duct exploration versus endoscopic sphincterotomy for concomitant gallstones and common bile duct stones: A metaanalysis of randomized controlled trials. Medicine (Baltimore) 2017; 96: e7925.

22. Vettoretto N, Arezzo A, Famiglietti F, Cirocchi R, Moja L, Morino M. Laparoscopic-endoscopic rendezvous versus preoperative endoscopic sphincterotomy in people undergoing laparoscopic cholecystectomy for stones in the gallbladder and bile duct. Cochrane Database Syst Rev 2018; 4: CD010507. 
23. Zhou Y, Zha W-Z, Wu X-D et al. Three modalities on management of choledocholithiasis: A prospective cohort study. Int'l J Surg 2017; 44: 269-73.

24. Pan L, Chen M, Ji L et al. The Safety and Efficacy of Laparoscopic Common Bile Duct Exploration Combined with Cholecystectomy for the Management of Cholecysto-choledocholithiasis: An Up-to-date Meta-analysis. Ann Surg 2018; 268: 247-53.

25. Koc B, Karahan S, Adas G, Tutal F, Guven H, Ozsoy A. Comparison of laparoscopic common bile duct exploration and endoscopic retrograde cholangiopancreatography plus laparoscopic cholecystectomy for choledocholithiasis: a prospective randomized study. Am J Surg 2013; 206: 457-63.

26. Cinar H, Ozbalci GS, Tarim IA et al. Factors affecting the conversion to open surgery during laparoscopic cholecystectomy in patients with cholelithiasis undergoing ERCP due to choledocholithiasis. Ann Ital Chir 2017; 88: 229-36.

27. Tzovaras G, Baloyiannis I, Zachari E et al. Laparoendoscopic rendezvous versus preoperative ERCP and laparoscopic cholecystectomy for the management of cholecysto-choledocholithiasis: interim analysis of a controlled randomized trial. Ann Surg 2012; 255: 435-9.

28. Rábago LR, Vicente C, Soler F et al. Two-stage treatment with preoperative endoscopic retrograde cholangiopancreatography (ERCP) compared with single-stage treatment with intraoperative ERCP for patients with symptomatic cholelithiasis with possible choledocholithiasis. Endoscopy 2006; 38: 779-86.

29. Tabone LE, Sarker S, Fisichella PM et al. To 'gram or not'? Indications for intraoperative cholangiogram. Surgery 2011; 150: 810-9.

30. Pierce RA, Jonnalagadda S, Spitler JA et al. Incidence of residual choledocholithiasis detected by intraoperative cholangiography at the time of laparoscopic cholecystectomy in patients having undergone preoperative ERCP. Surg Endosc 2008; 22: $2365-72$.

31. Nathanson LK, O'Rourke NA, Martin IJ et al. Postoperative ERCP versus laparoscopic choledochotomy for clearance of selected bile duct calculi: a randomized trial. Ann Surg 2005; 242: 188-92.

32. Zang J-F, Zhang C, Gao J-Y. Endoscopic retrograde cholangiopancreatography and laparoscopic cholecystectomy during the same session: feasibility and safety. World J Gastroenterol 2013; 19: 6093-7.

33. Tranter SE, Thompson MH. Comparison of endoscopic sphincterotomy and laparoscopic exploration of the common bile duct. $\mathrm{Br} J$ Surg 2002; 89: 1495-504.

34. Noble H, Tranter S, Chesworth T, Norton S, Thompson M. A randomized, clinical trial to compare endoscopic sphincterotomy and subsequent laparoscopic cholecystectomy with primary laparoscopic bile duct exploration during cholecystectomy in higher risk patients with choledocholithiasis. J Laparoendosc Adv Surg Tech A 2009; 19: 713-20.

35. Rogers SJ, Cello JP, Horn JK et al. Prospective randomized trial of $\mathrm{LC}+\mathrm{LCBDE}$ vs ERCP/S+LC for common bile duct stone disease. Arch Surg 2010; 145: 28-33.

36. Testoni PA, Mariani A, Aabakken L et al. Papillary cannulation and sphincterotomy techniques at ERCP: European Society of Gastrointestinal Endoscopy (ESGE) Clinical Guideline. Endoscopy 2016; 48: 657-83.

37. Rizzuto A, Fabozzi M, Settembre A et al. Intraoperative cholangiography during cholecystectomy in sequential treatment of cholecystocholedocholithiasis: To be, or not to be, that is the question A cohort study. Int'l J Surg 2018; 53: 53-8.

38. Tan C, Ocampo O, Ong R, Tan KS. Comparison of one stage laparoscopic cholecystectomy combined with intra-operative endoscopic sphincterotomy versus two-stage pre-operative endoscopic sphincterotomy followed by laparoscopic cholecystectomy for the management of pre-operatively diagnosed. Surg Endosc 2018; 32: 770-78.

39. Topal B, Vromman K, Aerts R, Verslype C, Van Steenbergen W, Penninckx F. Hospital cost categories of one-stage versus two-stage management of common bile duct stones. Surg Endosc 2010; 24: 413-6.

40. Jones M, Johnson M, Samourjian E, Schlauch K, Slauch K, Ozobia N. ERCP and laparoscopic cholecystectomy in a combined (one-step) procedure: a random comparison to the standard (two-step) procedure. Surg Endosc 2013; 27: 190712.

41. Fujimoto T, Tsuyuguchi T, Sakai Y et al. Longterm outcome of endoscopic papillotomy for choledocholithiasis with cholecystolithiasis. Dig Endosc 2010; 22: 95-100.

42. ElGeidie AA, ElShobary MM, Naeem YM. Laparoscopic exploration versus intraoperative endoscopic sphincterotomy for common bile duct stones: a prospective randomized trial. Dig Surg 2011; 28: 424-31.

43. Tang Z, Yang Y, Yang Z, Meng W, Li X. Early precut sphincterotomy does not increase the risk of adverse events for patients with difficult biliary access: A systematic review of randomized clinical trials with meta-analysis and trial sequential analysis. Medicine (Baltimore) 2018; 97: e12213.

44. Alexakis N, Connor S. Meta-analysis of one- vs. two-stage laparoscopic/endoscopic management of common bile duct stones. HPB (Oxford) 2012; 14: 254-9. 